\title{
Ergonomic constraints among nursing workers in the sectors of emergency care in two public hospitals in Brazil
}

\author{
Maria Goreth Bandeira ${ }^{\mathrm{a},}$, Raimundo Lopes Diniz ${ }^{\mathrm{b}}$ and Ana Hélia Sardinha ${ }^{\mathrm{c}}$ \\ a Post Graduate Program of Health and Environment, Federal University of Maranhão - Brazil \\ ${ }^{\mathrm{b}}$ Department of Design and Technology, Post Graduate Program of Health and Environment, Federal University \\ of Maranhão-Brazil,diniz@ufma.br \\ ${ }^{\mathrm{c}}$ Department of Nursing, Post Graduate Program of Health and Environment, Federal University of Maranhão- \\ Brazil,anahsardinha@ibest.com.br
}

\begin{abstract}
The goal of this study was to comprehensively identify ergonomic constraints among nursing workers in two public hospitals in Brazil. We used a qualitative research design and conducted interviews, field observation and performed a subjective questionnaire with nurses of emergency care sectors. The Cronbach $\alpha$ technique was used to determine the internal consistency of the questionnaire. Based on this qualitative study, we identified some ergonomic constraints related to work environment, biomechanics/anthropometrics, work organization and work station (hospital direction).
\end{abstract}

Keywords: nurses; ergonomic constraints; emergency care; public hospital

\section{Introduction}

Hospital ergonomics leads with studies in healthcare settings. It may help prevent injury and promote health, safety, and efficiency, and comfort in health care units to optimize human performance and improve patient health. Health care personnel are exposed to a remarkable array of biological, chemical, physical, and psychological hazards in their working environment (Mirbord et al. 1995). From this perspective, the nursing staff is one of the major categories of risk exposure to biological material, probably because it is a profession with one of the largest numbers of professionals in health services and to have direct contact in the care provided to patients (Brandão Jr., 2000).

Nursing has often been cited as an occupation exposed to a high number of risk factors that result in ergonomic constraints (Smith et al., 2011; Gurses and Carayon, 2010; Kim and Lee, 2010; Daraiseh et al.,
2010; Sheikhzadeh et al, 2009; Kee and Seo, 2007; Estryn-Behar, 2001; Hignett, 1996).

Diniz et al. (2001) conducted an ergonomic survey with the nursing of a hospital in Porto Alegre, Brazil. In general, the results appointed psychosocial problems, environmental conditions, organizational and communication. Mauro et al. (2002) conducted research with the nursing staff of a university hospital and proved discomforts of physical-environmental, psychosocial, and biomechanical. Paschoarelli et al. (2004) reported levels of discomfort at low back, upper and lower limbs, discomfort on legs, shoulders, cervical spine and thoracic spine, between other. Findings of Sheikhzadeh et al (2009) demonstrated a high prevalence of work-related musculoskeletal disorders, with lower back pain the most prevalent (84\%) complaint, followed by ankle/foot (74\%) and shoulder $(74 \%)$ pain among nurses and technicians in the surgical environment.

${ }^{*}$ Corresponding author. E-mail: goreth.bandeira@hotmail.com 
The consequences of occupational exposure to bloodborne pathogens, or biological risks, go beyond the physical damage, resulting psychosocial effects such as anxiety, frustration, feeling different and diverse. Such feelings experienced could result in psicossocial effects as insecurity, fear of contamination, anger, and even unrest. (Damasceno et al., 2006).

The aim of this study was to identify the main ergonomic constraints of work-related complaints among nurses and determine the factors related to ergonomic risks at the emergency care in two public hospitals in Brazil, based on a qualitative research design.

\section{Method}

This research was performed in two public hospitals in Sao Luis City, Brazil (Clementino Moura and Djalma Marques Hospitals), respectively in the sectors of emergency care. The nurses working in emergency care at both hospitals are composed of 95 personnel, and $80(84.2 \%)$ participated in the study. Participation was voluntary. All the participants are female. We collected data from nurses with various backgrounds (e.g., day versus night-shift nurse) and experience levels. Average experience of the participants as an emergency care nurse was 5 years. All the participants were registered nurses, working on $12-\mathrm{h}$ shifts.

\subsection{Procedures}

To develop an ergonomic intervention based on the participatory approach, it was adopted the MWA (Macroergonomic Work Analysis), by Guimarães (1999). The MWA is a participative ergonomics method and the macroergonomic approach is the core of this method. The MWA is composed of the five phases: phase 0 - Launching of the project (involves explaining the project objective, the phases, and the techniques to be used); phase 1 - Ergonomic evaluation (involves investigating and mapping the "Items of Ergonomic Demand" - IED - and includes the survey of users and field observations of the tasks using a questionnaire to identify ergonomic constraints and the user level of satisfaction); phase 2 - Ergonomic analysis and diagnosis (refers to the identification, analysis, and ranking of the mainly ergonomic constraints); phase 3 - Ergonomic design (involves proposals for modifications) and; phase 4 - Detailing and validation (involves the detailing and testing of the proposal for requirement needs). In this study we used only the first three phases of the MWA.

Data collection was based on field observations of the nurses tasks and workplaces. Nurses' opinion about their work was collected based on interviews and questionnaires. Interviews were performed based on follow single broad question: "Would you describe the main problems perceived from the perspective of working conditions?". 24 nurses were interviewed, corresponding to $30 \%$ of the total. For the purpose of prioritizing the IDEs, the order of mention of each item is used as weights for the reciprocal importance of their position. To the position of all items is assigned the weight $1 / \mathrm{p}$. Thus, the first factor mentioned receives the weight $1 / 1=1$, the second $1 / 2=0.5$, the third $1 / 3=0.33$, and so on. The trend of using the reciprocal function is to value the first items mentioned, and from the fourth item, the difference becomes less significant. The sum of the weights for each item will give rise to the ranking of importance of items and generally serve as a guide for developing a questionnaire to be completed by all participants (nurses).

The qualitative data obtained from the workers during the interviews and field observations provided the basis to develop the study's questionnaire. A 15 $\mathrm{cm}$ scale with three milestones (one at the beginning, one in the middle and the third at the end of the scale) was used. The questionnaire consisted of 25 questions grouped in five sections or constructs: 1 . 'Work Environment', 2. 'Hospital Direction', 3. 'Risk', 4. 'Organizational', and 5. 'biomechanics/anthropometrics'. Those who answered the questions were the same workers that also had been previously interviewed. The questionnaires were responded by 80 nurses. Also, It has been used the technique of Cronbach's alpha (Cronbach, 1951) in order to determine the level of internal consistency of the questionnaire applied. This $\alpha$ indicates the extent to which the scale was understood and points out whether the data are minimally reliable. An acceptable result is achieved when $\alpha$ is equal or higher than 0.55 . The data were processed with SPSS, version 17.0 for Windows.

\section{Results}

\subsection{Launching of the project}

Initially there was a meeting with the health and safety committee of the hospitals to present the objectives and procedures of the project. The re- 
search team met with the hospital board, committee, and union members to obtain their approval and support of the study. In accordance with the participatory approach, the multidisciplinary research team consisted of one psychologist, one occupational health nurse, one work safety technician, occupational therapist, occupational health manager and administrative agent.

\subsection{Interviews}

Table 1 describes the interviews results. It should be noted that nurses report experiencing more than one type of IED (ergonomic constraints). Patient handling was the item more reported totalizing a sum in 60,2 among nurses interviewed and the most frequent construct was 'Organizational'.

Table 1

Results of Interviews with nurses

\begin{tabular}{l|c|l|}
\multicolumn{1}{|c|}{ IED } & Total(Sum) & \multicolumn{1}{|c|}{ Construct } \\
\hline Patient handling & 60,2 & Biomechanics/anthropometrics \\
\hline Hight temperature & 20,2 & Work environment \\
\hline Cutting and piercing objects use & 18,3 & Risk \\
\hline Stress & 11,2 & Organizational \\
\hline Equipment not available & 10,9 & Hospital Direction \\
\hline Social rehationship & 10,2 & Organizational \\
\hline Insufficient work space & 9,5 & Biomechanics/anthropometrics \\
\hline Personal protective equipment not avalable & 8,7 & Hospital Direction \\
\hline Noisy work environment & 7,3 & Work environment \\
\hline Low quantity of courses and training & 7,6 & Hospital Direction \\
\hline Physical workload & 6,7 & Biomechanics/anthropometrics \\
\hline Patients with severe disease & 5,7 & Organizational \\
\hline Exposed to high biological risk & 5,7 & Risk \\
\hline Insufficient rest room & 5,3 & Hospital Direction \\
\hline Poor worksafe & 4,9 & Organizational \\
\hline Dimensions of hospital stretchers & 4,8 & Biomechanics/anthropometrics \\
\hline Occupational hygiene & 4,5 & Organizational \\
\hline Bullying events & 4,3 & Organizational \\
\hline Low number of staff & 3,9 & Organizational \\
\hline support of the head nurses & 3,9 & Organizational \\
\hline Crowded work environment & 3,7 & Organzational \\
\hline Drinking fountain & 3,4 & Hospital Direction \\
\hline Issues of hospital organization & 2,9 & Hospital Direction \\
\hline Distractions from family menbers & 2,7 & Organizational \\
\hline
\end{tabular}

In general, the mean ergonomic constraints were: patient handling, high temperature, cutting and piercing objects use, stress, equipment not available, social relationship and insufficient work space (table 1).

\subsection{Field observations}

Overcrowding of patients and hospital stretchers in the corridors (Figures 1), hospital stretchers with insufficient dimension (Figure 2).
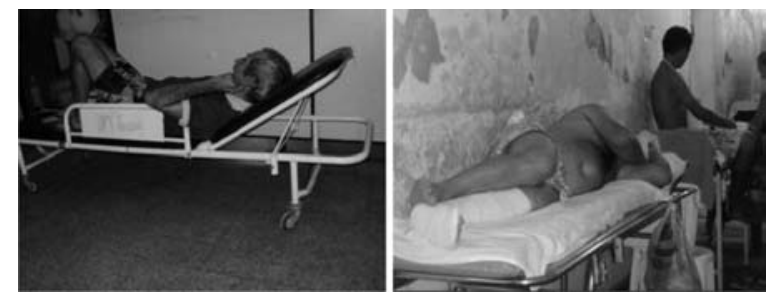

Figure 1 - Hospital stretchers with patients in the corridors

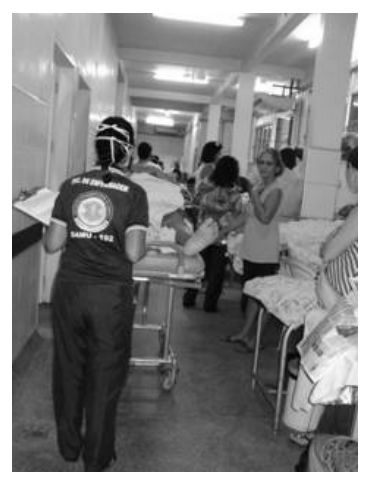

Figure 2 - Overcrowding of patients.

According to results of field observation nursing station with insufficient dimension, with a few seats, inadequate place of rest for the nurses, Supply area inadequately stocked, noisy work environment and high temperature, junk in the corners of walls, bloody sheets on the floor, Supply area is have dirty and disorganized (Figure 3).

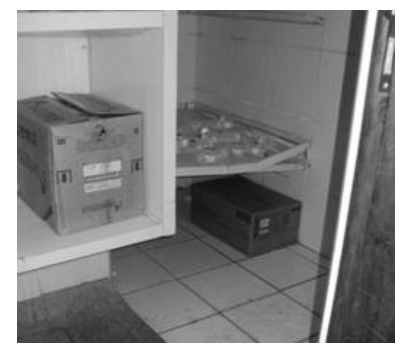

Figure 3 - Supply area.

During the observations was noted that following ergonomic constraints: the place where the medications are stored has insufficient dimension; equipment in poor condition, old and has poor maintenance; insufficient space to sit down and do paperwork; inadequate use of masks (figure 4) and venous medications without use of gloves (figure 5). 
The results of field observations corroborate references (Mirbord et al. 1995; Diniz et al., 2001; Mauro et al., 2002; Paschoarelli et al., 2004).

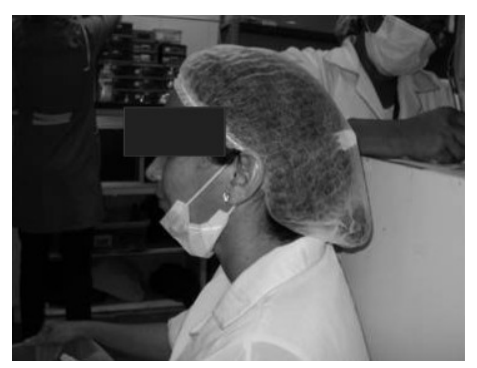

Figure 4 - Inadequate use of masks.

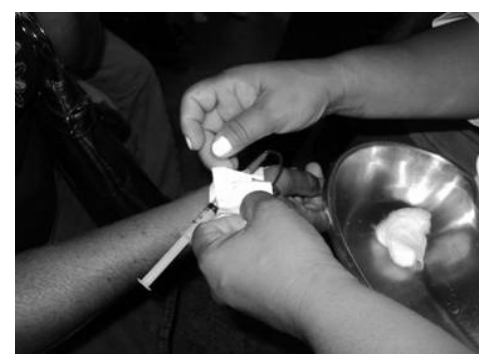

Figure 5 - venous medications without use of gloves

\subsection{Questionnaires}

With regard to Cronbach's alpha the result was, questionnaires had good internal consistency (0.67).

Figure 6 presents the results related to construct Work environment. The average was reduced for all items, and items Noise Temperature and presented the highest levels of dissatisfaction among nurses.

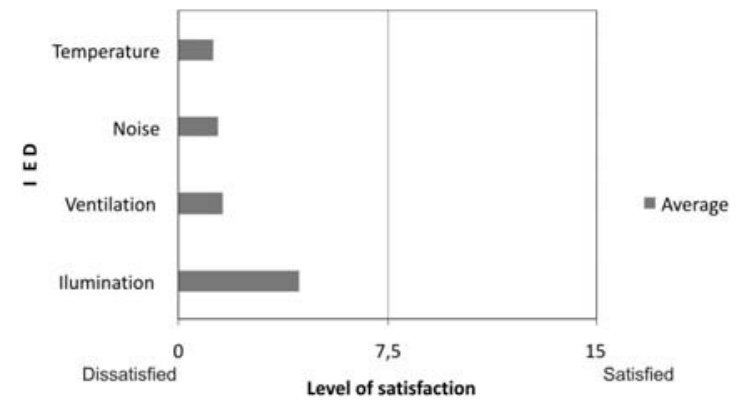

Figure 6 - Results related to construct Work Environment.

Nurses also complained insufficient workstation, fatigue related to tasks, physical workload and insufficient dimensions of hospital strechers (Figure 7).

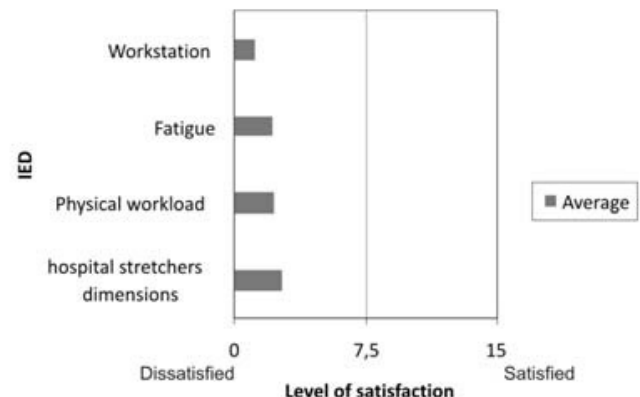

Figure 7 - Results related to construct Biomechanics/anthropometrics

The results to construct 'Risk' present higher levels of dissatisfaction related to 'Exposed to high biological risk', 'Salubrity' and 'Cutting and piercing object use' among respondents (nurses) (Figure 8).

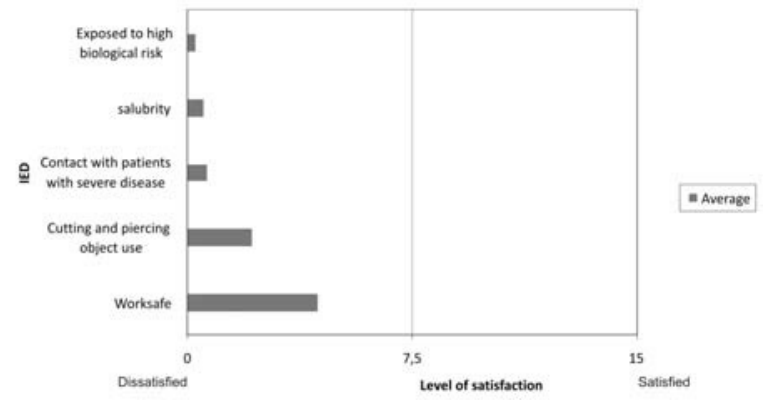

Figure 8 - Results related to construct Risk.

'Number of patients', 'Crowded work environment', 'Number of staff, 'Family members relations' and 'Stress' were the items with highest levels of dissatisfaction to construct 'Organizational' (Figure 9). 


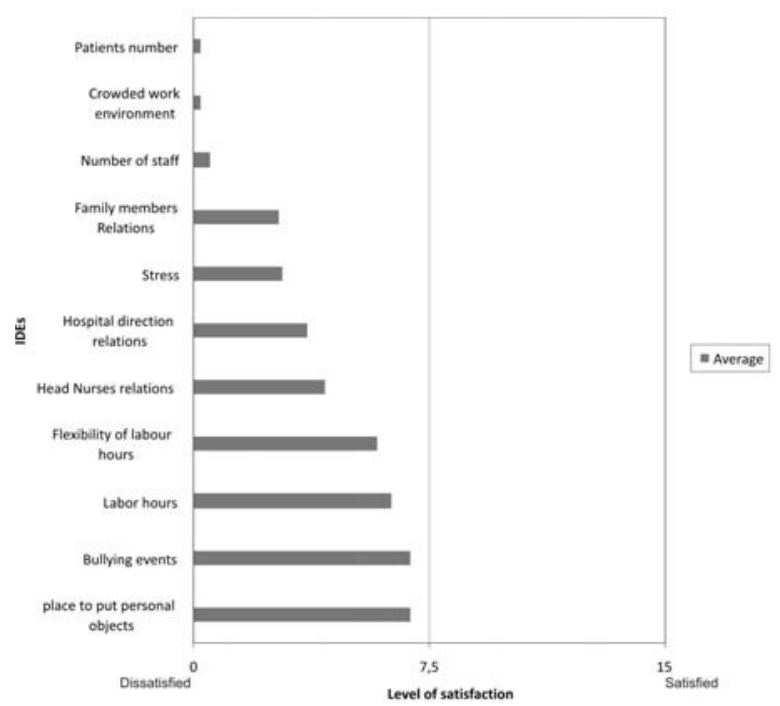

Figure 9 - Results related to construct 'Organizational'.

'Drinking fountain maintenance', Equipment not available, low quantity of courses and training, personel protective equipment not available, insufficient restroom and cloakroom, quality of food, place to meal and poor rest room were reported by nurses as dissatisfied items related to construct 'Hospital Direction' (Figure 10).

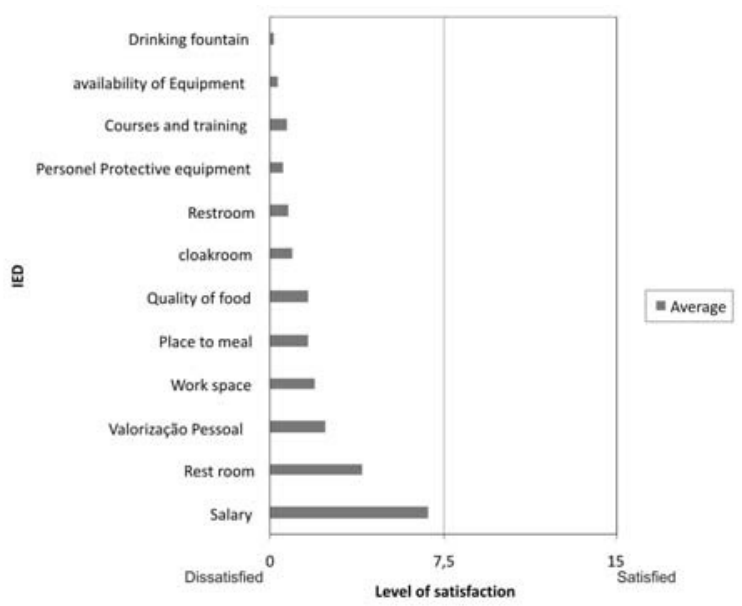

Figure 10 - Results related to construct 'Hospital Direction'

\section{Final considerations}

This study highlights the many IED or Ergonomic Constraints among nursing workers in Brazil. Based on this qualitative study, it were identified some er- gonomic constraints related to work environment, biomechanics/anthropometrics, work organization and work station (hospital direction).

The results corroborate the reviewed literature (Mirbord et al. 1995; Hignett, 1996; Diniz et al., 2001; Estryn-Behar, 2001; Mauro et al., 2002; Paschoarelli et al., 2004; Smith et al., 2011; Kee and Seo, 2007; Sheikhzadeh et al, 2009; Gurses and Carayon, 2010; Kim and Lee, 2010; Daraiseh et al., 2010), confirming ergonomic constraints between nurses in two public hospitals in Brazil, specifically in the sectors of emergency care.

It was evident that the working conditions offered to nursing personnel, could reflect the occurrence of accidents at work in the emergency care at the hospitals studied. Ergonomics professionals should continue to examine the specific aspects of nurses systems in detail and the risk factors, resulting in safer and higher quality care.

\section{Acknowledgments}

The authors are grateful to Kayra, Leandra Márcia, Maria Luiza for the data collection support

\section{References}

[1] Mirbod, S. M., Yoshida, H., Moyamoto, K., Miyashita, K., Inaba, R., Iwata, H. Subjective complaints in orthopedists and general surgeons. Int. Arch. Occup. Environmental Health. New York: Springer-Verlag, nº 67, 1995. Pp. 179 - 186.

[2] Brandão Jr., O. S. Biosafety and AIDS: the psychosocial dimensions of the accident with biological material at work in hospital [dissertation].Rio de Janeiro (RJ): Escola Nacional de Saúde Pública - Fundação Oswaldo Cruz; 2000. (in portuguese).

[3] Smith, Derek R. et al. Examining the Dimensions of Hospital Safety Climate and Psychosocial Risk Factors Among Japanese Nurses. Journal of Transcultural Nursing 22(3) (2011) $257-264$

[4] Gurses, Ayse; Carayon, Pascale. Exploring performance obstacles of intensive care nurses. Applied Ergonomics 40 (2009) 509-518.

[5] Kim, Soon-Lae; Lee, Jong-Eun. Development of an intervention to prevent work-related musculoskeletal disorders among hospital nurses based on the participatory approach. Applied Ergonomics 41 (2010) 454-460.

[6] Daraiseh, N.M.; Cronin, S.N.; Davis, L.S.; Shell, R.L.; Karwowski, W. Low back symptoms among hospital nurses, associations to individual factors and pain in multiple body regions. International Journal of Industrial Ergonomics 40 (2010) 19-24.

[7] Sheikhzadeh, Ali; Gore, Chaitrali; Zuckerman, Joseph; Nordin, Margareta. Perioperating nurses and technicians' perceptions of ergonomic risk factors in the surgical environment. Applied Ergonomics 40 (2009) 833-839. 
[8] Kee, Dohyung; Seo, Sun Rim. Musculoskeletal disorders among nursing personnel in Korea. International Journal of Industrial Ergonomics 37 (2007) 207-212.

[9] Estryn-Behar, Madeleine. Pre-Employment Screening Among Health Care Workers-Ethical Issues. International Journal of Occupational Safety and Ergonomics 2001, VOL. 7, $\mathrm{N}^{\mathrm{O}} .3$, 351-361.

[10] Hignett, S. Postural analysis of nursing work. Applied Ergonomics Vol 27, No. 3. (1996) pp. 171-17.

[11] Diniz, R. L.; Guimarães, L. B. M.; Ribeiro, D. L. J. Survey of ergonomic problems in nursing from a hospital in Porto Alegre.Anais ABERGO, Gramado, set. 2001. (in portuguese).

[12] Mauro, M.Y.C., Cupello, A.J. The work of hospital nursing. In: Congresso Brasileiro de Ergonomia, 11. Gramado, 2001.
Anais. Gramado: Associação Brasileira de Ergonomia ABERGO, 2001. (in portuguese)

[13]Paschoarelli, L. C., Corrêa, J.A., da Silva, J. C. P. Analysis of nursing occupational activities: aspect of the interface with medical and hospital equipment. In: Congresso Brasileiro de Ergonomia, 13. Fortaleza, 2004. Anais.Fortaleza:

[14] Associação Brasileira de Ergonomia - ABERGO, 2004. (in portuguese).

[15]Damasceno, A. P. et al. Accidents with biological material: the perception of professional rugged. Rev. Bras. Enferm. Brasília, v. 59, n. 1, p. 72-77, jan./fev. 2006. (in portuguese).

[16] Guimarães, L. B. M. Ergonomics of process. 2. ed. Porto Alegre: PPGEP/UFRGS, 1999. (in portuguese).

[17] Cronbach, L. J. Coefficient alpha and the internal structure of tests. Psychometrika, v. 16, n. 3, p. 297-334, 1951. 